\title{
Effects of Virgin Coconut Oil on the Histomorphometric Parameters in the Aortae and Hearts of Rats Fed with Repeatedly Heated Palm Oil
}

\author{
Kogilavani Subermaniam¹, Qodriyah Haji Mohd Saad², Yusof Kamisah², Faizah Othman ${ }^{3 *}$ \\ ${ }^{1}$ Allied Health Science College (Ministry of Health, Malaysia), Hospital Road, 47000 Sungai Buloh, Selangor, \\ Malaysia. \\ 2 Department of Pharmacology, Faculty of Medicine, Universiti Kebangsaan Malaysia, 56000 Kuala Lumpur, \\ Malaysia). \\ 3 Department of Anatomy, Faculty of Medicine, Universiti Kebangsaan Malaysia, 56000 Kuala Lumpur, \\ Malaysia. \\ * Corresponding author. Tel.: +603-91458637; email: faizahman@gmail.com \\ Manuscript submitted January 20, 2015; accepted March 20, 2015. \\ doi: 10.17706/ijbbb.2015.5.2.120-131
}

\begin{abstract}
The study was carried out to investigate the effects of virgin coconut oil (VCO) on histomorphometric changes in the aorta and heart of thermoxidized palm oil-fed rats. Thirty two male Sprague-Dawley rats were divided into four groups: control group fed with normal diet; 5 times heated palm oil-fed group (5HPO) fortified with $15 \%$ of 5HPO; VCO group supplemented with $1.43 \mathrm{ml} / \mathrm{kg}$ of VCO; and $5 \mathrm{HPO}+\mathrm{VCO}$ group. The treatment lasted for four months. Upon sacrifice, aortic and heart tissues were processed for light microscopic studies. Light microscopic studies showed thickened intima and media of the aorta in two out of eight rats in the 5HPO group only, while the rest of the rats did not show any thickening of either the intima or media of the aorta. Intima media area (IMA) in the VCO, 5HPO and $5 \mathrm{HPO}+\mathrm{VCO}$ was significantly increased compared to the control group. Circumferential wall tension (CWT) and tensile stress (TS) in the aorta of 5HPO showed a significant increase compared to the other groups. Cardiomyofibre width in 5HPO group showed a significant increase in size compared to the control, VCO and 5HPO+VCO groups. Cardiomyofibre nuclear size in the 5HPO group decreased in size significantly compared to the control, VCO and 5HPO+VCO groups. VCO supplementation at a dose of $1.43 \mathrm{ml} / \mathrm{kg}$ showed protective effects on the aorta and heart of thermoxidized palm oil fed rats.
\end{abstract}

Key words: Aorta, heart, histomorphometric changes, thermoxidized palm oil, virgin coconut oil.

\section{Introduction}

The diseases pertaining to cardiac and blood vessels that are categorized as cardiovascular diseases are on the rise and seem to be the major cause of increasing number of premature mortality worldwide [1]. This statement was supported by the International Cardiovascular Disease Statistics by World Health Organization (WHO) [2], Ref. [3] had reported that hypertension which is one of the cardiovascular diseases was itself a major factor for other cardiovascular diseases. In 2009, WHO had again reported that about 13\% of the total deaths globally were caused by hypertension and its complications [4]. According to the data presented by the National Health and Morbidity Survey III (NHMS III) in the year 2006, about $42.6 \%$ of the Malaysian population who were 30 years old and above suffered from hypertension and this number was 
shown to have increased compared to $32.9 \%$ in 1996 [5]. While there were many factors that contributed to hypertension, unhealthy dietary practice such as consuming deep fried foodstuffs was reported to be the contributing risk factor in hypertension [1]. The practice of recycling vegetable oil while preparing food was reported to be a common practice among Malaysians [6]. Hence this practice could contribute to the increasing number of victims with high blood pressure [7] in Malaysia.

Heating vegetable oil to a high temperature $\left(160-180^{\circ} \mathrm{C}\right)$ in which the oil is simultaneously exposed to air and moisture and hence undergoes a complex series of physical and chemical deterioration is called oil thermoxidation [8]. As a result of this oxidative deterioration, chemical composition of the vegetable oil gets affected, thus producing reactive oxygen species (ROS). As in the case of palm oil which has almost 50\% of unsaturated fatty acids, therefore is prone to be saturated at high temperature [9], [10] which means it could easily be oxidized by heat. ROS was reported to cause deleterious effects on normally functioning endothelial cells in balancing endothelin and nitric oxide [11] thus leading to the elevating risk of hypertension among consumers [7], [12]-[14]. As the ROS possess unpaired shell electron, it has high capability of damaging the cells and hence was reported to be the main cause of endothelial dysfunction [8], [15], [16]. Endothelial cells lining the inner surface, called the intimal layer of blood vessels are the main target in inflammatory diseases [17]. Endothelial dysfunction in many events has been reportedly manifested by impaired modulation of the vascular growth and dysregulation of the vasomotion as well as smooth muscle cell proliferation amongst others [17]-[19]. In addition to that, Ref. [20] had demonstrated that prolonged intake of repeatedly heated palm oil significantly increased blood pressure as well as the plasma angiotensin-converting enzyme (ACE). Following this, Ref. [21] had reported that a surge in the ACE was common in hypertensive experimental rats with cardiac remodelling. ACE is responsible in producing an active vasoconstrictor called angiotensin II. Therefore an increase in the activity of ACE eventually resulted in blood pressure increments and cardiomyofibre hypertrophy together with proliferation of the vascular cells [22].

Although there are some monounsaturated fatty acid (MUFA) rich vegetable oils reportedly alleviating hypertension [23], the detrimental effects of the concerned vegetable oils after multiple reheating on the etiology of hypertension could not be denied [14], [24]. Palm oil being the vegetable oil used in the present study contains both saturated fatty acids (SFA) and monounsaturated fatty acids (MUFA) at almost equal proportions [9]. Even though a number of previous studies had reported the correlation between hypertension and consumption of food rich in vegetable cooking oil that has been repeatedly heated, society did not appear to take heed in terms of reducing the usage of repeatedly heated palm oil [25]. These days, there are increasing anecdotal reports regarding utilization of plant-origin extracts to treat diseases as alternatives to modern medicine. One of the plant-origin extracts that has been researched for its medicinal property in ameliorating ailments is the virgin coconut oil (VCO). Recently, the characteristics and properties of the virgin coconut oil have been explored widely in view of its protective effects on health. The VCO that is being sourced directly from coconut milk (Cocos Nucifera Linn) by cold process under controlled temperature, has more benefits towards health compared to copra oil as it could preserve its therapeutic components such as phenolic acid and polyphenols that have antioxidant properties without being destroyed [26]. Ref. [9] reported that the majority of the fatty acid quantity in it was SFA and the quantity of the unsaturated fatty acids component was found to be minimal, hence has the capacity to remain more stable against peroxidation and exhibit low peroxide levels. In addition to that, the authors also reported that VCO had high contents of phenolic acid that enhanced its ability to scavenge and destroy the free radical activities thus revealing its antioxidant attributes.

VCO was also reported to reduce the total cholesterol, triglyceride, phospholipid, low density lipoprotein (LDL) and very low density lipoprotein but could increase the high density lipoprotein (HDL) in the serum 
and tissues [26]. In addition to that, Ref. [27] had reported that the polyphenol component found in VCO was capable of reducing lipid levels and LDL oxidation significantly. Whereas, Ref. [28] and Ref. [29] found that VCO had the ability to restrict inflammatory reactions hence consumption of VCO could destroy the complete immune factor reactions against endotoxins thus reducing the pro-inflammatory cytokine in vivo. Besides these, other studies had reported that the VCO had shown other therapeutic significance such as anti-inflammory, anti-thrombotic [30] and antioxidant properties [31]. Recently, Ref. [32] had reported virgin coconut oil was found to prevent blood pressure rise in rats fed with repeatedly heated palm oil but the mechanism was not explored. In addition to that, its capability in reducing lipid peroxidation and provide anti-inflammatory relief had been reported [26], [31]. Hence it is vital for researchers to explore its protective effects on the aortae and heart as it has been proven by local and international researchers that there is a correlation between hypertension and vascular as well as cardiac remodelling. Therefore, the present study was aimed to ascertain the cardiovascular protective effects of the VCO supplement on the aortae and heart tissue of the rats fed with repeatedly heated palm oil.

\section{Materials and Method}

\subsection{Palm Oil}

The palm oil used to feed the rats in this study was purchased from a local market (Cap Buruh, Lam Soon Edible Oil, Kuala Lumpur). It was utilized and reheated five times, according to the modified method of [33].

\subsection{Preparation of Heated Palm Oil Diet and Adminstration}

The heating process of the required palm oil was initiated using 2.5 litres of oil to fry $1 \mathrm{~kg}$ of sweet potatoes bought from the local market. The skins of the sweet potatoes were peeled off and the sweet potatoes were cut into slices and subsequently fried in a stainless-steel wok at about $180^{\circ} \mathrm{C}$ for 10 minutes. After frying for 10 minutes, the sweet potatoes were removed from the frying oil and the heated palm oil was allowed to cool for five hours. Then the entire frying process was repeated with a fresh new batch of 1 $\mathrm{kg}$ sweet potatoes in the same oil without adding on fresh palm oil into it. This frying process was repeated four times in order to get the five times heated oil. Standard rat chow (Gold Coin, Kepong, Malaysia) was ground and fortified with 15\% of the five times heated palm oil that had been prepared beforehand. The fortified rat chow was then shaped into pellets and dried in an oven at $80^{\circ} \mathrm{C}$ overnight. After 24 hours of drying, the diet was stored in a closed and dry cabinet and the same preparation was repeated weekly.

\subsection{Virgin Coconut Oil and Adminstration}

The virgin coconut oil used in the present study was purchased from a local manufacturer, the Organic Gain Sdn Bhd., Termerloh, Pahang, Malaysia. The rats were fed with fresh virgin coconut oil by means of oral gavage at a dose of $1.43 \mathrm{ml} / \mathrm{kg}$ of body weight/day [34].

\subsection{Animals}

Thirty two ( $n=32)$ adult male Sprague-Dawley rats aged three months old (weighing 200-280g) were used for the present study. Those rats were obtained from the Laboratory Animal Resource Unit, Universiti Kebangsaan Malaysia (UKM), Kuala Lumpur with prior ethical clearance from Universiti Kebangsaan

Malaysia Animal Committee
(FP/ANAT/2012/FAIZAH/26-SEPTEMBER/457-SEPTEMBER-2012-AUGUST-2014). The handling and care including all management of the rats were conducted according to the recommended guidelines and experimental protocols approved by Universiti Kebangsaan Malaysia Animal Ethics Committee (UKMAEC). The experimental rats were housed individually in polyethylene with stainless-steel covered cages. They were kept at room temperature of $27^{\circ} \mathrm{C} \pm 2^{\circ} \mathrm{C}$ with 12 -hours light-dark cycle in the department of Anatomy 
Animal House. All the experimental rats had free access (ad libitum) to food and tap water throughout the experimental period of four months. They were acclimatized for one week prior to the administration of the test diet and supplements.

\subsection{Study Design}

Thirty two (n=32) male Sprague-Dawley rats were randomly assigned into four groups that comprised eight rats in each group and they were given the following course of diet and supplement: (i) normal rat chow (basal diet) as control group, (ii) normal rat chow (basal diet) and supplement of VCO (1.43 ml $/ \mathrm{kg} /$ day body weight) as VCO group, (iii) rat chow fortified with $15 \%$ of $5 \mathrm{HPO}$ as $5 \mathrm{HPO}$ group and (iv) rat chow fortified with $15 \%$ of $5 \mathrm{HPO}$ and supplement of VCO $(1.43 \mathrm{ml} / \mathrm{kg} /$ day body weight $)$ as $5 \mathrm{HPO}+\mathrm{VCO}$ group. After four months of experimentation, the rats were sacrificed and their aortae (arch) and heart tissues were harvested. The aortae (arch) and left ventricular heart tissues were cleaned and they were immediately preserved in the $10 \%$ phosphate buffered formalin solution prior to the processing of the tissues for histomorphometric study.

\subsection{Heart Histomorphometry}

The cardiac (left ventricle) tissue was fixed in 10\% phosphate buffered formalin solution immediately after harvesting for 24 to 48 hours and then the tissues were processed using automatic tissue processor, Microm STP1201-1. Thereafter, the tissues were embedded (blocked) in Paraplast Plus (Sigma-Aldrich, St. Louis, MO, USA) and $5 \mu \mathrm{m}$ thickness tissue cross sections were accomplished using LEICA RM2235, Leica Microsystems, Germany. The sectioned tissues were stained with haematoxylin and eosin to identify the myofibre width and its nuclear size. Digital images of the left ventricular sections were obtained (JPEG format, 24-bit colour, $2560 \times 1920$ pixels) with a MicroPublisher 5.0 RTV camera (Q Imaging, Surrey, BC, Canada) and a Nikon Eclipse 80i microscope (Nikon Corporation, Tokyo, Japan). The same tissues were analysed (under $\times 200$ magnification) using software Image-Pro Plus version 7.0 (Media Cybernetics, Silver Spring, MD, USA).

Three slides were prepared from each block of the left ventricular tissue samples. The measurement of the myofibre and its nuclear size was accomplished according to the method described by previous researchers [35], [36] with some modification. A field of 10,000 $\mu \mathrm{m}$ size was determined and used as standard to avoid lameness in the result among the samples. Four readings were obtained for each tissue section that is at the position of $0^{\circ}, 90^{\circ}, 180^{\circ}$ and $270^{\circ}$. Therefore, twelve measurements from each cardiac sample were averaged to obtain the individual values and those measurements were carried out by two blinded assessors.

\subsection{Aortic Histomorphometry}

The aortic arches were fixed in 10\% phosphate buffered formalin solution immediately after harvesting for 24 to 48 hours and then the tissues were processed using the automatic tissue processor, Microm STP1201-1. Thereafter, the tissues were embedded (blocked) in Paraplast Plus (Sigma-Aldrich, St. Louis, MO, USA) and $5 \mu \mathrm{m}$ thickness tissue cross sections were accomplished using LEICA RM2235, Leica Microsystems, Germany. The sectioned tissues were stained with Verhoeff-Van Gieson to identify the elastic fibres and as well as the smooth muscle cells. Digital image of the aortic (arch) sections were obtained (JPEG format, 24-bit colour, $2560 \times 1920$ pixels) with a MicroPublisher 5.0 RTV camera (Q Imaging, Surrey, BC, Canada) and a Nikon Eclipse 80i microscope (Nikon Corporation, Tokyo, Japan). The tissues were analysed using software Image-Pro Plus version 7.0 (Media Cybernetics, Silver Spring, MD, USA). Three slides were obtained from each block of the aortic arch tissue samples. The aortic morphometric measurements including intima-media thickness (IMT), intima-media thickness ratio (IMT Ratio), intima-media area (IMA), 
lumen diameter, lamellar units, circumferential wall tension (CWT) and tensile stress (TS) were carried out according to the method described by previous researchers [14], [37], [38].

Four measurements of the IMT in each image were taken at the position of $0^{\circ}, 90^{\circ}, 180^{\circ}$ and $270^{\circ}$ by drawing a line across the tunica intima and media and thereafter, an average value was calculated from the four measurements of each image. Therefore, each sample's reading was an averaged value of twelve corresponding measurements. Lumen area, identified as $(a)$ was estimated by drawing a line over the circle delimited by the inner surface of the intima layer of the aortic arch. Thereafter, lumen diameter, identified as (d) was calculated using the $a$ value i.e. $d=(2 \sqrt{a}) / \pi$, in which $a$ was expressed in $\mathrm{mm}^{2}$, the value of was 3.14 and $d$ (lumen diameter) as in $\mathrm{cm}$. The mean value of cross-sectional area IMA was estimated as IMA = $\left[\pi\left(d / 2+\mathrm{IMT}^{2}\right]-\left[\pi(d / 2)^{2}\right]\right.$. The tunica intima-media thickness ratio (IMT ratio) was calculated as IMT Ratio = Intima thickness/media thickness. The number of elastic fibres lamellae (lamellar units) in the tunica media was counted and CWT was estimated as CWT $=\operatorname{MSBP} \times(d / 2)$, in which the CWT was expressed as in dyne/cm and MSBP (mean systolic blood pressure) as in dynes $/ \mathrm{cm}^{2}$. TS was estimated as TS $=\mathrm{CWT} / \mathrm{IMT}$ and the reading was expressed as in dyne $/ \mathrm{cm}^{2} \mathrm{IMT}$ in $\mathrm{cm}$.

\subsection{Statistical Analyses}

All data were expressed as mean \pm SEM. Normality test of data was determined using Shapiro-Wilk test. The mean comparisons among groups were analysed using one-way analysis of variances (ANOVA) followed by Games-Howell post-hoc test. A value of $p<0.05$ was considered as statistically significant. All statistical analyses were performed using the Statistical Package for Social Sciences (SPSS) version 20.0 software (SPSS Inc., Chicago, IL, USA).

\section{Results}

\subsection{Heart Histomorphometry}

\subsubsection{Cardiomyofibre width}

Left ventricular sections from rats fed with 5HPO showed significant increment $(p<0.05)$ in their cardiomyofibre width at the end of the study as compared to the other three groups. However, cardiomyofibre width did not differ significantly between the control, VCO and 5HPO+VCO groups (Fig. 1, panel A).

\subsubsection{Cardiomyofibre nucleus size}

Left ventricular sections from the rats fed with 5HPO showed significant decrement $(p<0.05)$ in their cardiomyofibre nucleus size as compared to all other three groups (Fig. 1, panel B).

\subsubsection{Cardiomyofibre nucleus count}

The cardiomyofibre nucleus count in the left ventricular sections of the rats in all four groups did not differ significantly (Fig. 1, panel C).

\subsection{Aortic Histomorphometry}

\subsubsection{Intima-media thickness (IMT)}

Aortic sections from the rats fed with 5HPO and 5HPO+VCO showed significant increment $(p<0.05)$ in their IMT compared to those in the control and VCO groups. Whereas, the aortic IMT of the rats fed $5 \mathrm{HPO}+\mathrm{VCO}$ showed significant decrement $(p<0.05)$ compared to IMT of the rats in 5HPO group (Table 1$)$.

\subsubsection{Intima-media thickness ratio (IMT ratio)}

The aortae of the rats fed with 5HPO showed significant increase $(p<0.05)$ in their IMT ratio as 
compared to the rats in control, VCO and 5HPO+VCO groups (Table 1).

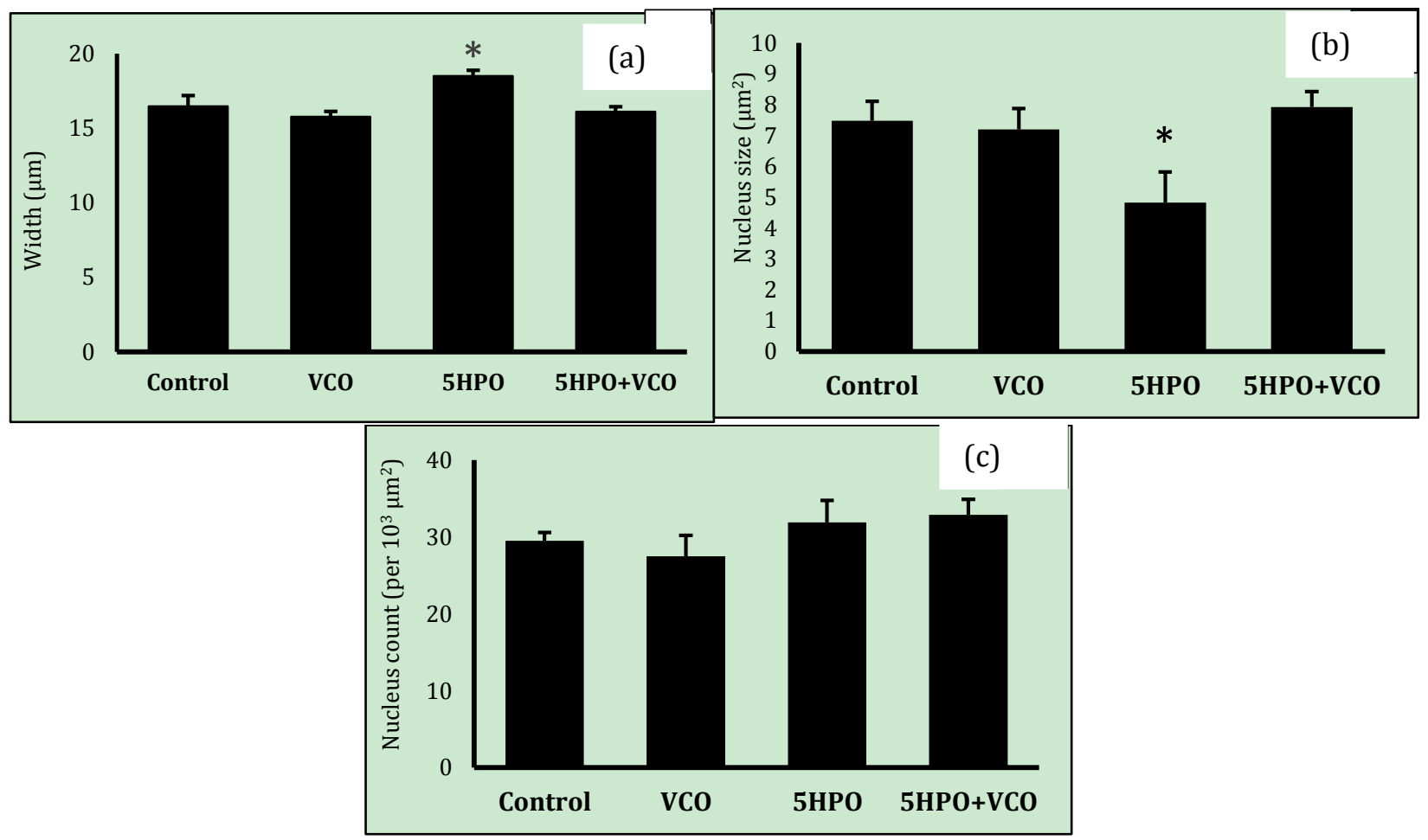

Fig. 1. Heart histomorphometric measurements. (a) cardiomyofibre width; (b) cardiomyofibre nucleus size; (c) cardiomyofibre nucleus count.

Data are expressed as mean \pm SEM. VCO: virgin coconut oil; 5HPO: five-times-heated palm oil; 5HPO+VCO: five-times-heated palm oil and virgin coconut oil.

$* p<0.05$ versus control, $\mathrm{VCO}$ and $5 \mathrm{HPO}+\mathrm{VCO}$.

\subsubsection{Lumen diameter}

There was no significant difference in the lumen diameter of the aortae among the four groups of rats noted at the end of the study (Table 1).

\subsubsection{Intima-media area (IMA)}

The rats fed with VCO, 5HPO and 5HPO+VCO showed significant increment $(p<0.05)$ in IMA of their aortae compared to those in the control group. Whereas, the aortic IMA of the rats fed VCO showed significant decrease $(p<0.05)$ as compared to the rats in 5HPO group (Table 1).

\subsubsection{Lamellar units}

The lamellar unit of the aortae in the rats of all the four groups did not differ significantly (Table 1).

\subsubsection{Circumferential wall tension (CWT)}

The CWT of the aortic wall among the rats fed 5HPO showed significant increase $(p<0.05)$ compared to the reading found among rats in the control, VCO and 5HPO+VCO groups. At the same time, we observed that the rats fed with 5HPO+VCO showed significant decrease $(p<0.05)$ in their CWT reading compared to the rats fed with $5 \mathrm{HPO}$ (Table 1).

\subsection{Tensile Stress (TS)}

The tensile stress in the aortic wall of the rats fed with 5HPO showed significant increment $(p<0.05)$ 
compared to those rats in the control group. Whereas, the rats fed with 5HPO+VCO showed significant decrement in their aortic wall tensile stress compared to the rats in 5HPO group (Table 1).

Table 1. Aortic Histomorphometric Measurements

\begin{tabular}{cccccccc}
\hline \hline Groups & $\begin{array}{c}\text { Intima-Media } \\
\text { Thickness } \\
(\mu \mathrm{m})\end{array}$ & $\begin{array}{c}\text { Intima-Media } \\
\text { Thickness } \\
\text { Ratio }\end{array}$ & $\begin{array}{c}\text { Lumen } \\
\text { diameter } \\
(\mathrm{mm})\end{array}$ & $\begin{array}{c}\text { Intima-Media } \\
\text { Area }\left(\mathrm{mm}^{2}\right)\end{array}$ & $\begin{array}{c}\text { Lamellar } \\
\text { units }\end{array}$ & $\begin{array}{c}\text { Circumferential } \\
\text { Wall Tension } \\
\left(10^{4} \text { dine } / \mathrm{cm}^{2}\right)\end{array}$ & $\begin{array}{c}\text { Tensile Stress } \\
\left(10^{4}\right. \\
\left.\text { dine } / \mathrm{cm}^{2}\right)\end{array}$ \\
\hline Control & $115.64 \pm 3.09$ & $0.02 \pm 0.001$ & $\begin{array}{c}0.85 \pm \\
0.02\end{array}$ & $0.35 \pm 0.02$ & $10.10 \pm 0.49$ & $0.45 \pm 0.02$ & $38.44 \pm 1.30$ \\
VCO & $127.60 \pm 2.87$ & $0.02 \pm 0.003$ & $\begin{array}{c}0.95 \pm \\
0.04\end{array}$ & $0.43 \pm 0.01^{*}$ & $10.38 \pm 0.26$ & $0.51 \pm 0.02$ & $40.80 \pm 2.04$ \\
$5 \mathrm{HPO}$ & $168.12 \pm 9.46$ & $0.06 \pm$ & $0.94 \pm$ & $0.59 \pm 0.05$ & $9.35 \pm 0.44$ & $0.81 \pm 0.04 * \# \S$ & $49.14 \pm$ \\
& $* \#$ & $0.005^{*} \S$ & 0.04 & $* \#$ & & $2.29 * \# \S$ \\
5 HPO+VCO & $145.50 \pm 7.54$ & $0.02 \pm 0.002$ & $0.90 \pm$ & $0.49 \pm 0.04 *$ & $10.40 \pm 0.46$ & $0.49 \pm 0.03$ & $33.59 \pm 2.63$ \\
& $* \# \dagger$ & & 0.05 & & & & \\
\hline \hline
\end{tabular}

Data were expressed as mean \pm SEM. VCO: virgin coconut oil; 5HPO: five-times-heated palm oil; 5HPO+VCO: five-times-heated palm oil and virgin coconut oil;

$* p<0.05$ versus control; $\quad \# p<0.05$ versus VCO; $\dagger p<0.05$ versus 5HPO; $\S p<0.05$ versus

\section{Discussion}

The present study was carried out to ascertain the capability of the virgin coconut oil in protecting against vascular and cardiac tissue remodeling in which both the aortic wall [13], [14] and cardiomyofibre [12] had been proven to undergo injury and inflammation as a result of prolonged consumption of repeatedly heated palm oil. Our study demonstrated significant increase in the cardiomyofibre width and significant decrease in its nuclear size in the rats fed with 5HPO as compared to those in the control, VCO and $5 \mathrm{HPO}+\mathrm{V}$ whereas, the nuclear size was also reduced significantly in the rats of 5HPO group compared to control, VCO and 5HPO+VCO. Reference [12] has reported in her study that cardiac tissue of rats fed with 5 HPO showed necrosis. This result could be a sequel of cardiac hypertrophy resulting from the increased blood pressure, as reported by reference [39]. It could still be at the initial stage of structural changes in the cardiac tissue as a compensatory mechanism reacting to the high pressure load which might later trigger hypertrophy of the cardiomyofibres via cellular hypertrophy. However [40] reported that increased blood pressure caused cardiac hypertrophy and remodeling process due to hemodynamic overload in the heart. In addition to those reports, Ref. [41], [42] suggested that dilation and myocyte hyperplasia may be associated with the process of cardiac tissue remodeling. Reference [12] has reported chronic consumption of reheated palm oil induced cardiac toxicity but on the other hand, [43] suggested those events could be the results of toxicant production that had been induced by the lipid peroxidation of the palm oil. Lipid peroxidation is the oxidative degradation of the lipids during which the free radicals destroy the cells as a result of attacking the electrons from lipids of the cell membrane. Nuclear size diminution observed in the cardiomyofibre of the 5HPO group rats without a change in the number of the nuclei may be suggestive of the protective effects of the VCO that possesses potent antioxidant components such as phenolic acid and polyphenol fraction besides high content of lauric acid among other saturated fatty acids [9] that has been reported to reduce the total cholesterol to high density lipoprotein cholesterol ratio [44]. On the other hand, that may be an indicator of an early step towards pyknosis, which leads to nuclear fragmentation and eventually death [27].

Interestingly, the rats in the 5HPO+VCO group showed significantly lower cardiomyofibre width and increased size of the nuclei as compared to those in the 5HPO group. This may be suggestive of the protective effects of the VCO that possesses potent antioxidant components such as phenolic acid and polyphenol fraction besides high content of lauric acid among other saturated fatty acids [9] that has been 
reported to reduce the total cholesterol to high density lipoprotein cholesterol ratio [44]. On the other hand, Ref. [27] has reported increase in antioxidant status in the rats fed VCO supplement. Though the results of control, VCO and 5HPO+VCO did not differ significantly among them, 5HPO+VCO showed that the minimal VCO dosage of $1.43 \mathrm{ml} / \mathrm{kg} /$ day body weight used was only able to initiate the protection and this could be probed further in future research with higher dosage of VCO supplementation. We postulated that VCO supplementation would have been able to prevent the histopathology changes in the cardiomyofibre but however, our study results demonstrated that its cardioprotective effect seemed to be at the early stage only and we did not study the mechanism of its protective effects to identify the chemical pathways involved.

As for the aortic histomorphometric results, our study findings demonstrated a significant deleterious effect of the 5HPO and an extent of protective effects of the VCO on the aortae. It was learned that prolonged ingestion of 5HPO led to vascular remodeling that was evidenced by significant increased thickness (IMT), intima-media thickness ratio (IM Ratio) and area (IMA) of the aortic wall compared to the control group. This result was similar in pattern with a previous study by Ref. [14]. They suggested that prolonged ingestion of heated palm oil caused vascular hypertrophy remodeling. In addition to that, we observed that IMT of the aortic wall of the rats in the VCO reduced significantly compared to 5HPO and 5HPO+VCO and more interestingly, what we would like to highlight here is that the IMT of the aortic wall of the rats in 5HPO+VCO demonstrated significant reduction compared to 5HPO. This result may indicate that the VCO at the minimum dosage was able to initiate the protective effect against the vascular hypertrophic remodeling.

Despite the increase in IMT, IMA and IMT ratio of the aortic wall in 5HPO fed rats, it was observed that the lamellar unit did differ among the groups and this could suggest that the thickening and large intima-media area was a result of vascular smooth muscle cells hypertrophy. This result was similar to the study by Ref. Ref. [14] which had also suggested similar postulation of the IMT and IMA increment. On the other hand, an increase in both the IMT and IMA without change in the lumen diameter is suggestive of hypertrophic outward remodeling in the aortic wall of the rats in 5HPO group and this finding was again similar to that of Ref. [14]. Though the supplementation of VCO did not differ significantly in the aspect of IMA among the $5 \mathrm{HPO}+\mathrm{VCO}$ group aortic wall compared to 5HPO, but VCO only supplemented group showed that the VCO had demonstrated its protective effects on the aortic wall by demonstrating lower IMA. Again, this protective effect of VCO could be the result of antioxidant properties that perform scavenging activity on the ROS that has been proven to play a major role in the vascular remodeling [13], [14], [32]. This could be because of the minimal dosage that was not good enough to overcome the deleterious effects caused by the $5 \mathrm{HPO}$ on the aortic wall of those rats in the group.

Further, the CWT and TS of the aortic wall of the rats fed with 5HPO were significantly increased compared to the control, $\mathrm{VCO}$ and 5HPO+VCO. This observation was not in keeping with the one reported by Ref. [14] where the TS did not differ but the CWT result was increased significantly as in the present study. TS is the tension applied per unit of the thickness and acts perpendicularly to the wall of the aortae whereas, CWT is the force that acts longitudinally and in circumferential directions opposing the distending effects of blood pressure [38]. Ref. [14] reported the increase in CWT could have been due to the elevated blood pressure among the rats in the same group i.e. 5HPO. However, we could not relate in that manner as we did not study the blood pressure of the same rats. Nevertheless, both TS and CWT were observed to be significantly reduced in the aortic wall of the rats fed with 5HPO+VCO. Therefore, it is interesting that the VCO did reduce the aortic wall tension and the tension applied to each unit of the intima-media thickness.

\section{Conclusion}

In conclusion, VCO supplementation at a dose of $1.43 \mathrm{ml} / \mathrm{kg}$ showed protective effects on the vascular and cardiac tissue remodeling resulted from the prolonged consumption of repeatedly heated palm oil by the 
experimental rats. However, further studies may be necessary to test the higher dosage of VCO supplementation for better protective effects and secondly to ascertain whether VCO supplementation could be used to treat hypertension as vascular remodeling had been correlated to increased blood pressure local and international researchers.

\section{Acknowledgment}

This study was supported and funded by Universiti Kebangsaan Malaysia Medical Faculty Research Grant FF398-2012 and DLP2013-005. The authors thank Madame Siti Nor Ain Bakhtiar, of Department of Anatomy, Faculty of Medicine, and Mr Ng Chun Yi, of the Department of Pharmacology, Faculty of Medicine, Universiti Kebangsaan Malaysia, Kuala Lumpur, for their kind help and technical assistance and Assoc Prof Dr Koh Ong Hui, Department of Psychological Medicine, University Malaya for his editorial assistance. There is no conflict of interest regarding each of the authors involved in this research work.

\section{References}

[1] McCance, K. L., \& Huether, S. E. (2006). Pathophysiology: The Biologic Basis of Disease in Adults and Children, (5 $5^{\text {th }}$ ed.) St. Louis, Missouri: Elsevier Mosby.

[2] World Health Organization. (2008). International Cardiovascular Disease Statistics. Geneva, Switzerland: World Health Organization.

[3] Iyer, V. C., \& Brown, L. (2010). The DOCA-Salt hypertensive rats as a model of cardiovascular oxidative and inflammatory stress. Current Cardiology Reviews, 6(4), 291-297.

[4] World Health Organization. (2009). Global Health Risks: Mortality and Burden of Disease Attributable to Selected Major Risks. Geneva, Switzerland: World Health Organization, 2009.

[5] Hypertension on the rise (2010). The Star. Retrieved January 29, 2010, from http:// http://www.thestar.com.my/story.

[6] Azman, A., Suondoh, M. S., Xuan, C. S., Abdul Patah, N., Mokhtar, K., Mohd Fahami, N. A., et al. (2010). Level of awareness amongst the general public regarding usage of repeatedly heated cooking oil in Kuala Lumpur, Malaysia. International Medical Journal, 17, 310-311.

[7] Soriguer, F., Rojo-Martinez, G., Dobarganes, M. C., et al. (2003). Hypertension is related to the degradation of dietary frying oils. The American Journal of Clinical Nutrition, 78(6), 1092-1097.

[8] Harrison, D. G., Gongora, M. C., Guzik, T. J., \& Widder, J. (2007). Oxidative stress and hypertension. Journal of the American Society of Hypertension, 1(1), 30-44.

[9] Marina, M., Che Man, Y. B., Nazimah, S. A. H., \& Amin, L. (2009). Antioxidant capacity and phenolic acids of virgin coconut oil. International Journal of Food Sciences and Nutrition, 60(S2), 114-123.

[10] Azlan, A., Prasad, K. N., Khoo, H. E., et al. (2010). Comparison of fatty acids, vitamin E and physicochemical properties of Canarium odontophyllum Miq. (dabai), olive and palm oils. Journal of Food Composition and Analysis, 23(8), 772-776.

[11] Williams, M. J., Sutherland, W. H., McCormick, M. P., de Jong, S. A., Walker, R. J., \& Wilkins, G. T. (1999). Impaired endothelial function following a meal rich in used cooking fat. Journal of American College of Cardiology, 33(4), 1050-1055.

[12] Leong, X. F., Aishah, A., Nor Aini, U., Das, S., \& Jaarin, K. (2008). Heated Palm oil causes rise in blood pressure and cardiac changes in heart muscle in experimental rats. Journal of Archives of Medical Research, 39, 567-572.

[13] Adam, S. K., Das, S., \& Jaarin, K. (2009). A detailed microscopic study of the changes in the aorta of experimental model of postmenopausal rats fed with repeatedly heated palm oil. International Journal of Experimental Pathology, 90, 321-327. 
[14] Ng, C. Y., Yusof, K., Othman, F., Jubri, Z., Hj Mohd Saad, Q., \& Jaarin, K. (2012). Involvement of inflammation and adverse vascular remodeling in the blood pressure raising effect of repeatedly heated palm oil in rats. International Journal of Vascular Medicine, 10 pages.

[15] Pennathur, S., \& Heinecke, J. W. (2007). Oxidative stress and endothelial dysfunction in vascular disease. Current Diabetes Reports, 7(4), 257-264.

[16] Zalba, G., Fortuño, A., San, J. G., Moreno, M. U., Beloqui, O., \& Díez J. (2007). Oxidative stress, endothelial dysfunction and cerebrovascular disease. Cerebrovascular Diseases, 24, 24-29.

[17] Bautista, L. E. (2003). Inflammation, endothelial dysfunction, and the risk of high blood pressure: Epidemiologic and biological evidence. Journal of Human Hypertension, 17(4), 223-230.

[18] Balakumar, P., Kaur, T., \& Singh, M. (2008). Potential target sites to modulated vascular endothelial dysfunction: Current perspectives and future directions. Toxicology, 245(1-2), 49-64.

[19] Grover-Páez, F., \& Zavalza-Gómez, A. B. (2009). Endothelial dysfunction and cardiovascular risk factors. Diabetes Research and Clinical Practice, 84(1), 1-10.

[20] Leong, X. F., Salimon, J., Mustafa, M. R., \& Jaarin, K. (2012). Effect of repeatedly heated palm olein on blood pressure-regulating enzymes activity and lipid peroxidation in rats. Malaysian Journal of Medical Sciences, 19(1), 20-29.

[21] Varagic, J., Ahmad, S., Voncannon, J. L., et al. (2012). Nebivolol reduces cardiac angiotensin II, associated oxidative stress and fibrosis but not arterial pressure in salt-loaded spontaneously hypertensive rats. Journal of Hypertension, 30, 1766-1774.

[22] Taylor, A. A., \& Pool, J. L. (2011). Clinical role of direct renin inhibition in hypertension. American Journal of Therapeutics, 19, 204-210.

[23] Alonso, Á., Ruiz-Gutierrez, V., \& Martínez-González, M. Á. (2006). Monounsaturated fatty acids, olive oil and blood pressure: Epidemiological, clinical and experimental evidence. Public Health Nutrition, 9, 251-257.

[24] Leong, X. F., Mustafa, M. R., Das, S., \& Jaarin, K. (2010). Association of elevated blood pressure and impaired vasorelaxation in experimental Sprague-Dawley rats fed with heated vegetable oil. Journal of Lipids in Health and Disease, 9, 66.

[25] Azman, A., Mohd Shahrul, S., Chan, S. X., Noorhaliza, A. P., Khairunnisak, M., Azlina N., et al. (2012). Level of knowledge, attitude and practice of night market food outlet operators in Kuala Lumpur regarding the usage of repeatedly heated cooking oil. Medical Journal of Malaysia, 67(5), 91-101.

[26] Nevin, K. G., \& Rajamohan, T. (2004). Beneficial effects of virgin coconut oil on lipid parameters and in vitro LDL oxidation. Journal of Clinical Biochemistry, 37, 830-835.

[27] Nevin, K. G., \& Rajamohan, T. (2006). Virgin coconut oil supplemented diet increases the antioxidan status in rats. Journal of Clinical Food Chemistry, 99, 260-266.

[28] Sadeghi, M. M., Collinge, M., Pardi, R., \& Bender, J. R. (2000). Simvastatin modulates cytokine-mediated endothelial cell adhesion molecule induction: Involvement of an inhibitory G protein. Journal of Immunology, 165, 2712-2718.

[29] Wan, J. M., \& Grimble, R. F. (1987). Effect of dietary linoleate content on the metabolic reponse of rats to Escherichia coli endotoxin. Journal of Clinical Science, 72, 383-385.

[30] Intahphuak, S., Khonsung, P., \& Panthong, A. (2010). Anti-inflammatory, analgesic and antipyretic activities of virgin coconut oil. Journal of Pharmaceutical Biology, 48(2), 151-157.

[31] Nevin, K. G., \& Rajamohan, T. (2008). Influence of virgin coconut oil on blood coagulation factors, lipid levels, and LDL oxidation in cholesterol fed Sprague-Dawley rats. European Journal of Clinical Nutrition and Metabolicl, 3, 1-8. 
[32] Nurul-Iman, B. S., Kamisah, Y., Jaarin, K., \& Qodriyah, H. M. S. (2013). Virgin coconut oil prevents blood pressure elevation and improves endothelial functions in rats fed with repeatedly heated palm oil. Evidence -Based Complementary and Alternative Medicine, 2013, Article ID 629329, 7 pages.

[33] Owu, D. U., Osim, E. E., \& Ebong, P. E. (1998). Serum liver enzyme profile of Wistar rats following chronic consumption of fresh or oxidized palm oil diets. Acta Tropica, 69(1), 65-73.

[34] Fife, B. (2005). Coconut Cures: Preventing and Treating Common Health Problems with Coconut, (4th ed.) New York: Avery Trade.

[35] Anversa, P., Beghi, C., Kikkawa, Y., \& Olivetti, G. (1985). Myocardial response to infarction in the rat: morphometric measurement of infarct size and myocyte cellular hypertrophy. American Journal of Pathology, 118(3), 484-492.

[36] Burkhardt, J. E., Ochoa, R., Kowsz, K. P., Levin, S., \& Jakowski, A. B. (1996). Changes in rat heart histomorphometry due to two-week dietary restriction. Toxicology and Pathology, 24, 636-638.

[37] Fernandes-Santos, C., Mendonca, L. D. S., \& Mandarim-de-Lacerda, C. A. (2009). Favorable cardiac and aortic remodeling in olmesartan-treated spontaneously hypertensive rats. Journal of Heart and Vessel, 24(3), 219-227.

[38] Moraes-Teixeira, J. D. A., F'elix, A., Fernandes-Santos, C., Moura, A. S., Mandarim-de-Lacerda, C. A., \& de Carvalho, J. J. (2010). Exercise training enhances elastin, fibrillin and nitric oxide in the aorta wall of spontaneously hypertensive rats. Journal of Experimental and Molecular Pathology, 89(3), 351-357.

[39] Leonard, B. L., Smaill, B. H., \& LeGrice, I. J. (2012). Structural remodelling and mechanical function in heart failure. Microscopy and Microanalysis, 18, 50-67.

[40] Leong, X. F., Mohd Najib, M. N., Das, S., Mustafa, M. R., \& Jaarin, K. (2009). Intake of repeatedly heated palm oil causes elevation in blood pressure with impaired vasorelaxation in rats. Tohoku Journal of Experimental Medicine, 219, 71-78.

[41] Sonnenblick, E. H., \& Anversa, P. (1999). Models and remodeling: Mechanisms and clinical implication. Cardiologia, 44, 609-619.

[42] Mandarim-de-Lacerda, C. A., \& Meirelles Pereira, L. M. (2000). Numerical density of cardiomyocytes in chronic nitric oxide synthsis inhibition. Pathobiology, 68, 36-42.

[43] Edem, D. O. (2002). Palm oil: Biochemical, physiological and toxicological aspects: A review. Plant Food for Human Nutrition, 57, 319-341.

[44] Micha, R., \& Mozaffarian, D. (2010). Saturated fat and cardiometabolic risk factors, coronary heart disease, stroke and diabetes: A fresh look at the evidence. Lipids, 45, 893-905.

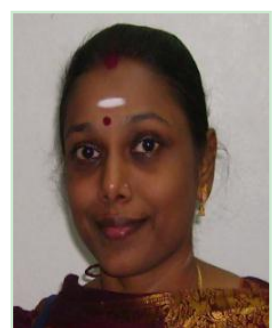

Kogilavani Subermaniam was born in Perak on the 25th May 1973. She received her nursing degree from University of Malaya, Malaysia in 2005. She obtained her master's degree of medical science (anatomy) from Universiti Kebangsaan Malaysia in 2014 and the master's degree of nursing science from University of Malaya, Malaysia. Her research interests are in protective effect of virgin coconut oil on cardiovascular system and also in maternal child health with gynaecology nursing. She is currently lecturing anatomy and physiology at Allied Science College under Ministry of Health, Malaysia. 


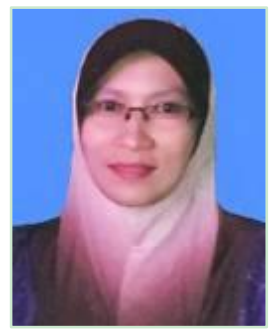

Qodriyah Haji Mohd Saad was born in Kedah, Malaysia on the $18^{\text {th }}$ June 1967. She received her degree in bachelor of medicine and surgery (MBBS) from the University of Malaya, Malaysia in 1993. She obtained her doctor of philosophy, PhD (pharmacology), from the Universiti Kebangsaan Malaysia in 2006. Her niche area of interest is looking into the effects of consumption of natural products, particularly herbs and edible oils on the cardiovascular system and also stress enzyme.

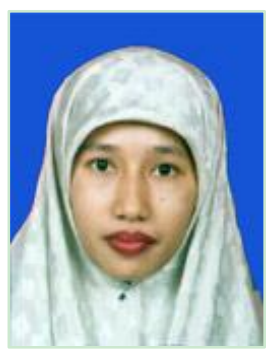

Yusof Kamisah was born in Terengganu, Malaysia on the $22^{\text {nd }}$ January 1970. She received her degree in bachelor of science (Hons) (pharma) from the Universiti Kebangsaan Malaysia in 1993. She obtained her doctor of philosophy, $\mathrm{PhD}$ (pharmacology), from the Universiti Kebangsaan Malaysia in 2000. Her niche area of interest is looking into the effects of consumption of natural products, particularly herbs and edible oils on the cardiovascular system and liver disorders.

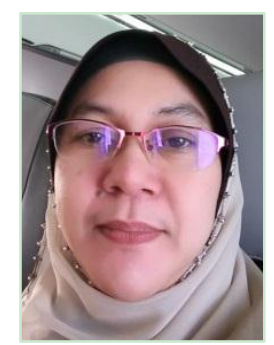

Faizah Othman was born in Johore, Malaysia on the 22nd May 1962. She received her medical degree (MD) from the Universiti Kebangsaan Malaysia in 1987. She obtained her doctor of philosophy (PhD) from the same university in 2001. Her niche area of interest is looking into the effects of consumption of natural products, particularly herbs and edible oils on the cardiovascular system. 